Revista Destaques Acadêmicos, Lajeado, v. 10, n. 3, 2018. ISSN 2176-3070

DOI: http://dx.doi.org/10.22410/issn.2176-3070.v10i3a2018.1891

http://www.univates.br/revistas

\title{
AS PERCEPÇÕES DE TRABALHADORES TÉCNICO ADMINISTRATIVOS SOBRE O PROJETO DE CUIDADOS EM SAÚDE DO TRABALHADOR DA UNIVATES
}

\author{
Marcelo Brancher Gravina ${ }^{1}$, Eduardo Sehnem²
}

Resumo: A saúde do trabalhador ao longo dos anos vem se tornando de suma importância para a área da saúde. A produtividade no trabalho muitas vezes está ligada à uma rotina de posturas, gestos e atividades mentais que obrigam o corpo a submeter-se às demandas do sistema produtivo, causando consequências ao sistema osteomuscular. É neste âmbito que a Fisioterapia tem atuação primordial, tanto no tratamento dessas lesões quanto na prevenção das mesmas. O objetivo do presente estudo foi avaliar a percepção de funcionários técnico administrativos quanto às ações do Projeto de Cuidados em Saúde do Trabalhador da Univates. Caracteriza-se como uma pesquisa transversal, de campo, de caráter quantitativo. Os dados foram obtidos através do envio de um questionário via lista de e-mails da Instituição, o qual era constituído de nove perguntas fechadas e ficou disponível por um período de dez dias. No total, 115 trabalhadores responderam ao mesmo. Em relação ao tempo de trabalho, $32,17 \%$ trabalha na Instituição por um período de 3 a 5 anos. A maior porcentagem em relação à idade dos trabalhadores assinalada foi de 34,78\% entre 21 a 25 anos. 52,2\% dos participantes revelaram que não só estudam como também trabalham na Instituição. De acordo com os resultados obtidos, é possível concluir que o Projeto conseguiu atingir boa parte dos trabalhadores, bem como o seu objetivo de melhorar a qualidade da jornada de trabalho dos mesmos.

Palavras-chave: Cuidados em Saúde. Trabalhadores. Ginástica Laboral. Ergonomia. Questões Posturais.

\section{INTRODUÇÃO}

A atenção frente ao trabalhador e sua saúde é um assunto que, com o passar dos últimos anos, se tornou mais importante e relevante para os empregadores. Com o aumento dos Distúrbios Osteomusculares Relacionados ao Trabalho (DORT), e das Lesões por Esforço Repetitivo (LER), o empregador

1 Estagiário do curso de Fisioterapia, UNIVATES, marcelo@gravina.com.br

2 UNIVATES, eduardosehnem@univates.br 
também se depara com o aumento dos afastamentos trabalhistas, redução da produtividade e, consequentemente, dos lucros. Segundo dados da Previdência Social, entre 2011 e 2013, os principais motivos de recebimento de auxíliosdoença foram as doenças do sistema osteomuscular e do tecido conjuntivo (INSS, 2014).

A produtividade no trabalho muitas vezes está ligada à uma rotina de posturas, gestos e atividades mentais que obrigam o corpo do trabalhador a submeter-se às demandas do sistema produtivo, causando consequências dentro e fora do ambiente de trabalho, gerando diversos impactos negativos sobre a saúde do mesmo.

A esfera social do trabalho incorpora na abordagem fisioterapêutica a reflexão das representações dos impactos que as disfunções musculoesqueléticas exercem sobre a saúde do trabalhador. Dessa forma, é prevista uma série de ações que visam abranger fatores organizacionais, socioculturais e territoriais, com objetivo de fortalecer métodos possíveis de controle desse agravo (MELO, 2017). Dentro desses métodos, se destacam a ergonomia e a ginástica laboral, objetos de trabalho utilizados com os funcionários técnico administrativos participantes desse estudo.

De acordo com Veronessi (2014), a ergonomia visa adequar sistemas de trabalhos às características das pessoas que neles operam. Nos projetos de sistemas de produção, a ergonomia faz convergir os aspectos de segurança, desenvolvimento e de qualidade de vida, por meio da sua metodologia específica, a análise ergonômica de trabalho.

Diversos estudos têm analisado a efetividade das intervenções de programas de promoção à saúde do trabalhador. Dentre essas intervenções, destaca-se a ginástica laboral, também chamada de ginástica de pausa, que é o exercício físico no próprio local de trabalho. Durante a atividade, são realizados alongamentos, exercícios ativos e exercícios resistidos, bem como exercícios para promover equilíbrio e relaxamento. As abordagens também podem ser realizadas através de intervenções educativas, e-mails, aconselhamentos individuais ou coletivos (GRANDE et al., 2013).

No Brasil, o ano de 1969 marcou o início da ginástica laboral em empresas multinacionais. Atualmente, grande parcela de empresas e indústrias possuem profissionais contratados para realizar esse trabalho, tendo em vista os benefícios conhecidos e já comprovados de tal atividade (SERRA; PIMENTA; QUEMELO, 2014). Dentre esses benefícios, podemos citar melhora e maior resistência à fadiga, melhora do condicionamento físico, redução de tensões musculares, melhoria das relações interpessoais, promoção de melhor qualidade de vida e motivação, gerando assim, um aumento na produtividade e redução no número de afastamentos trabalhistas.

É neste âmbito que a Fisioterapia tem atuação primordial, tanto no tratamento dessas lesões quanto na prevenção das mesmas, através de análises 
e adaptações ergonômicas e da ginástica laboral. Conforme Bau e Klein (2009), a existência do fisioterapeuta dentro das empresas desenvolve uma nova cultura de consciência, melhoria da produção e, consequentemente, de economia para as mesmas.

Dessa forma, esse trabalho teve como objetivo avaliar a percepção de trabalhadores técnico administrativos quanto às ações do projeto de Cuidado em Saúde do Trabalhador da Univates. Esse projeto é realizado por alunos e docentes do curso de Fisioterapia e Educação Física, que atuam em diversos setores da Universidade, realizando adaptações ergonômicas quando necessárias e a prática de ginástica laboral, com duração média de 10 minutos por dia.

\section{MÉTODOS}

O presente estudo é uma pesquisa transversal, de campo, de caráter quantitativo. Participaram da pesquisa funcionários técnico administrativos da Instituição. Os dados foram obtidos através do envio de um questionário constituído de nove perguntas fechadas, o qual foi estruturado na plataforma de questionários Google. As cinco primeiras questões tinham como objetivo caracterizar a amostra quanto à faixa etária, tempo de trabalho na Instituição, se estuda na Instituição e se realiza atividade de ginástica laboral. As três questões seguintes, foram para avaliação das atividades de ginástica laboral, com as respostas apresentadas na forma de Escala de Likert. A última questão visava avaliar os motivos da participação ou não na ginástica laboral, sendo possível o participante marcar mais de uma opção.

Foram convidados a participar do estudo todos os trabalhadores que ocupam cargos enquadrados como técnico administrativo na Instituição. A realização do estudo foi autorizada pela Coordenação do setor de Recursos Humanos, através da assinatura da carta de Anuência. O envio do questionário foi realizado pelo contato com o setor de comunicação interna e utilizada a lista de e-mails dos funcionários. Foram excluídos aqueles que não estiveram na Instituição no período de disponibilização do questionário, seja por período de férias, licença saúde ou outro motivo. O tempo estimado para responder as nove questões era aproximadamente de cinco minutos.

O estudo foi aprovado pelo Comitê de Ética em Pesquisa (COEP), da Instituição, estando de acordo com a Resolução do CNS no 466/12. O Termo de Consentimento Livre e Esclarecido (TCLE) foi anexado junto ao questionário. Ao aceitar participar da pesquisa, o funcionário confirmou seu consentimento no próprio questionário. Caso se recusasse a participar, ele poderia indicar no mesmo questionário, ou simplesmente não responder. Após enviar o questionário via lista de e-mails da Instituição, o mesmo ficou disponível por um período de dez dias. A participação no estudo não repercutiu em qualquer tipo de exposição a constrangimentos ou riscos físicos. 


\section{RESULTADOS}

Após a disponibilização do questionário por um período de dez dias, 115 trabalhadores responderam o mesmo, de um total 675 trabalhadores técnicos administrativos que receberam o convite, o que corresponde a um total de $17 \%$ de respondentes. Os resultados estão apresentados na forma de porcentagem, conforme distribuição das respostas. Em relação ao tempo de trabalho, 32,17\% trabalha na Instituição por um período de 3 a 5 anos, $29,57 \%$ trabalha a até 2 anos; $14,78 \%$ de 6 a 10 anos, $12,17 \%$ de 11 a 15 anos; $8,70 \%$ de 16 a 20 anos e $2,61 \%$ trabalham a 21 anos ou mais.

A idade dos participantes era acima de 17 anos. A maior porcentagem em relação a idade dos funcionários assinalada, foi de 34,78\% entre 21 a 25 anos, sendo as demais de 26,96\%, para idade de 26 a 30 anos, $24,35 \%$, de 31 a 40 anos, $5,21 \%$ de 41 a 50 anos, $4,35 \%$ mais de 51 anos e a faixa etária menos marcada foi de 17 a 22 anos, com 4,35\%.

Mais da metade dos funcionários participantes da pesquisa também estudam na universidade, totalizando $52,17 \%$. Os demais $47,83 \%$ não estudam na mesma.

Quando questionados em relação à avaliação do seu posto de trabalho, $67,83 \%$ responderam que já havia sido avaliado o seu local de trabalho por algum estagiário e 32,17\% responderam que não havia sido avaliado o seu posto de trabalho.

Em relação à participação na atividade de ginástica laboral, 58,26\% responderam que participam semanalmente do projeto e $41,74 \%$ responderam que não participam da ginástica laboral quando são convidados.

Quando questionados quantas vezes por semana os entrevistados são convidados a participar das atividades, 26,09\% responderam que são convidados uma vez na semana, 20,87\% são convidados 5 vezes por semana, $20,00 \%$ são convidados 4 vezes na semana, 16,52\% são convidados 3 vezes na semana e $16,52 \%$ responderam que são convidados 2 vezes por semana a participar das atividades de ginástica laboral.

Quanto à cordialidade da equipe com os participantes do projeto, $47,83 \%$ relataram que a equipe é totalmente cordial com estes, 26,96\% assinalaram que a equipe é cordial, mas determinados aspectos, deixam a desejar. Para 18,26\% a equipe é cordial, porém em determinados momentos, essa cordialidade não aparece, mas na maioria das vezes, a equipe é cordial. Para 5,21\% a equipe não é cordial com os participantes do projeto e para $1,74 \%$ a equipe tem muito a melhorar em relação à cordialidade.

Quanto à avaliação dos exercícios escolhidos pela equipe, 39,13\% assinalaram que estes são agradáveis e de fácil execução, para $27,83 \%$ os exercícios são agradáveis, porém, poderiam ser de melhor execução, 22,61\% os participantes acreditam que os exercícios poderiam ser melhores escolhidos 
pelos estagiários, 6,08\% acreditam que os exercícios são inadequados e 4,35\% acreditam que há muito a melhorar em relação aos exercícios.

Quanto aos fatores que estimulam ou dificultam a participação na atividade de ginástica laboral, 33\% $(n=38)$ dos participantes responderam que não possuem dificuldades em realizar a atividade, conseguindo realizá-la todas as vezes propostas. Em relação aos fatores que dificultam a participação, predominou a incompatibilidade de horário para a realização das atividades com um total de $33 \%(n=38)$ das respostas, seguido de não gostar de realizar a atividade $15,7 \%(\mathrm{n}=18)$, o grupo não passar no setor do trabalhador $14,08 \%$ $(\mathrm{n}=17)$ e não gostar da exposição durante a atividade $7 \%(\mathrm{n}=8)$. Ressalta-se que nesta questão os participantes poderiam indicar mais de uma opção.

\section{DISCUSSÃO}

Os distúrbios osteomusculares aparecem após uma soma de esforços e traumas repetitivos, caracterizados por dor crônica e afecções, de forma isolada ou associada, com ou sem degeneração dos tecidos, afetando principalmente os membros superiores, região escapular e pescoço (SANCHES et al., 2010). Os funcionários avaliados nesse estudo, de caráter técnico-administrativo na Instituição, possuíam a característica de permanecer por muito tempo sentados, utilizando computador e telefone, conforme afirmado anteriormente, onde o maior tempo de trabalho dentro da empresa pode ocasionar quadros crônicos de LER/DORT.

Em relação aos trabalhadores participantes deste estudo, a grande maioria é jovem (66,1\% possui menos de 30 anos), tendo pouco tempo de atuação na empresa. E, além de trabalharem na Instituição, também estudam na mesma (52,2\%). Santos e Gimenez (2015) mostram em seu estudo, que no período de crescimento econômico do Brasil, entre 2004 e 2012, com evidentes efeitos positivos sobre o mercado de trabalho e sobre a estrutura social brasileira, ampliaram-se os espaços de inserção laboral dos jovens. Não somente os espaços foram ampliados, como a qualidade dos postos de trabalho oferecidos evoluiu positivamente, em razão da melhoria geral da estrutura de emprego e de renda.

Trabalhar na Universidade onde estudam propicia, além de facilidades em relação à locomoção de trabalhar e estudar em um único local (com ambientes próximos uns dos outros), desconto na mensalidade e, em alguns casos, já estar inserido na área de trabalho escolhida para cursar a graduação. Para Santos e colaboradores (2007), em conformidade com o efeito da educação dos pais, a renda familiar também influencia a decisão do jovem quanto ao trabalho.

Ainda sobre os trabalhadores mais jovens, os padrões motores irão ser formulados após a repetição dos movimentos, os quais mudam com o aprendizado motor e com a experiência prévia do indivíduo. $\mathrm{O}$ treinamento 
promove a aprendizagem, tornando o indivíduo habilidoso naquilo que a tarefa exige de seu comportamento motor. Com o passar do tempo e a aquisição da prática nas suas metodologias de trabalho, esses trabalhadores podem desenvolver estratégias de proteção, e com isso apresentar melhores prognósticos para dores, desconfortos e lesões osteomusculares relacionadas ao trabalho (GIANGIARDI, 2013);

No presente estudo, 9,5\% (n=11) dos participantes possui mais de 41 anos, $23,5 \%(n=27)$ responderam que estão na universidade de 11 a 21 anos ou mais. A expectativa de vida vem aumentando no Brasil nos últimos anos, juntamente com a melhora da qualidade de vida e avanço da medicina e tecnologias. Dessa forma, as pessoas estão trabalhando por mais tempo e, devido ao processo natural de envelhecimento, os tecidos se tornam mais suscetíveis à lesões, com a diminuição de massa óssea, dando às estruturas cartilaginosas, redução da elasticidade dos ligamentos, perda de força muscular e infiltração gordurosa nos tecidos, diminuindo a capacidade destes em manter suas funções normais, gerando assim um aumento nos índices de distúrbios osteomusculares relacionados à atividade laboral (MELO et al., 2017).

Quando questionados em relação à associação do trabalho e estudo, mais da metade dos funcionários (52,2\%) realizam ambas atividades. Considerando as atividades predominantes na Instituição, bem como o exercício da função de estudante, estes passam a maior parte do tempo sentados. $O$ sedentarismo traz diversas consequências à saúde. Além de favorecer o aparecimento de doenças cardiovasculares, ele também favorece o aparecimento de lesões relacionadas ao trabalho, justamente pelos tecidos se encontrarem enfraquecidos e despreparados para a jornada de trabalho (SANTOS et al., 2007).

A mecanização do trabalho favorece o comportamento hipocinético no ambiente laboral, aumentando a exposição também às doenças cardiovasculares. A prática regular de atividade física proporciona efeitos fisiológicos e psicológicos positivos, entre eles a melhoria da auto-estima, diminuição do estresse e da ansiedade, melhoria das funções cognitivas e da socialização, assim como maior sensação de bem-estar (ROCHA et al., 2011). Dessa forma, é primordial difundir para esses trabalhadores a importância de uma vida ativa, não sedentária, onde os exercícios físicos se tornam aliados para a prevenção de lesões relacionadas ao trabalho e um futuro envelhecimento saudável.

Em relação à postura sentada, esta gera alterações nas estruturas musculoesqueléticas da coluna lombar, como o aumento da pressão interna no núcleo do disco intervertebral, estiramento dos ligamentos, pequenas articulações e nervos. Além disso, também reduz a circulação de retorno venoso dos membros inferiores, provoca tensão nos músculos isquiotibiais e glúteos (causando retroversão da pelve), horizontalização do ângulo sacral, retificação da lordose lombar e aumento das cargas compressivas no disco intervertebral (VITTA et al., 2013). 
Um sistema musculoesquelético treinado, de uma pessoa que realiza atividades físicas, com certeza sofrerá menos desses impactos do que o sistema musculoesquelético de uma pessoa sedentária (GALANO, 2011).

Através do sedentarismo, diversas patologias podem surgir em consequência, sendo as mais comuns à hipertensão arterial, diabetes, obesidade, aumento do colesterol e infarto do miocárdio. As causas associadas à obesidade são várias: hábito de comer demais e erroneamente, influência genética, meio ambiente e nível de atividade física. As causas genéticas não podem ser modificadas, mas as causas ambientais e comportamentais podem ser alteradas com orientação de um profissional capacitado (CARVALHO, 2014).

Em relação às avaliações do posto de trabalho, 32,2\% dos trabalhadores não tiveram seus postos de trabalho avaliados. A avaliação ergonômica é muito importante, pois pode identificar os fatores de risco dos postos de trabalho. Através desta, observa-se a adequação do espaço de trabalho ao funcionário, visando proporcionar melhor condição laboral. O método OWAS foi desenvolvido como ferramenta das análises das principais posturas inadequadas, podendo conter imagens fotográficas e filmagens, métodos descritivos e observacionais. O método RULA é uma adaptação do método OWAS, contendo outras variáveis, como: força, repetição e amplitude de movimento articular, sendo recomendado analisar sobrecargas concentradas em membros superiores e inferiores durante as atividades (SANTOS, 2017).

É necessário ressaltar que, antes da aplicação do Programa de Ginástica Laboral, levou-se em conta a avaliação dos fatores organizacionais relativos aos fatores tempo de trabalho, pausa para descanso, revezamento de tarefas, relacionamento interpessoal, repetitividade de movimento com os membros superiores, visando um programa adequado às reais necessidades do grupo participante da pesquisa, assim como os aspectos sintomatológicos (dor) e nível de satisfação (SANTOS et al., 2007).

Quando os trabalhadores não realizam as trocas de posturas em seu ambiente de trabalho, alguns problemas ocorrem, como o afastamento do trabalhador da sua função e, em muitos casos, da empresa. Este afastamento para a empresa não é encarado de forma positiva, pois esta deverá arcar com partes das despesas até o retorno do trabalhador ao seu posto de trabalho. O trabalhador se atua com alguma patologia, acaba acarretando em baixa produtividade. Em muitos casos, a empresa possui duas saídas: demissão do funcionário ou a troca de setor deste (Lei N 6.367, 1976).

Quanto aos riscos ergonômicos a adoção de postura corporal inadequada, a monotonia/repetitividade do trabalho e o esforço físico dispendido na execução das atividades rotineiras foram os fatores identificados pela maioria dos trabalhadores (FERNANDES; MARZIALE, 2014).

As exigências laborais, nomeadamente as exigências quantitativas e o ritmo de trabalho imposto apresentaram-se como fatores relevantes para o 
desenvolvimento de lesões musculoesqueléticas (LME) nas zonas do pescoço, ombros e região lombar. Esses tipos de lesões também correlacionaram-se com funções mais repetitivas ou em que o colaborador permanecia muito tempo na mesma posição, solicitando constantemente os mesmos grupos musculares ou funções que implicassem levantamentos e manipulações frequentes (FERNANDES; PEREIRA, 2016).

Conceitualmente, a ginástica laboral é uma modalidade de atividade física praticada dentro da empresa, também conhecida como ginástica compensatória, ginástica do trabalho ou de pausa. Seu objetivo maior é criar um espaço para a melhoria do condicionamento físico dos trabalhadores, quebrando o ritmo das tarefas repetitivas e da monotonia e, primordialmente, prevenir o surgimento de doenças ocupacionais. Os exercícios são realizados por meio de sessões que normalmente duram de 10 a 15 minutos e são conduzidas no próprio local de trabalho, antes, durante ou após o expediente de trabalho (SERRA; PIMENTA; QUEMELO, 2014).

Quanto ao convite dos trabalhadores em realizar o projeto de saúde do trabalhador, a grande maioria respondeu que era convidado uma vez por semana a participar das atividades, em um total de 26,1\% $(n=30)$. Em qualquer idade, a prática de atividade física é uma atitude essencial para melhorar a saúde física e mental dos indivíduos (OMS, 2010).

Em relação à equipe que aplica a ginástica laboral ser cordial e ou não, $47,8 \%(\mathrm{n}=55)$, responderam que está é cordial e que se mostra com postura adequada para a realização das atividades. Para que estes trabalhadores tenham uma boa qualidade de vida principalmente dentro de seu trabalho, é necessária uma compensação adequada e justa, condições de segurança e saúde no trabalho, oportunidade imediata para a utilização e desenvolvimento da capacidade humana, oportunidade para crescimento contínuo, dentre outros. O que se observa é que o trabalhador fica distante de seus familiares e de situações da vida particular por jornadas longas ou entre dois ou três empregos, tornando-se alienado, irritado e estressado (ANDRADE; ANDRADE; LEITE, 2015).

A insatisfação e o desânimo pelo trabalho realizado geram desconforto, e este, somado ao estado de cansaço ou fadiga, torna-se um importante fator de desgaste mental no trabalho dos profissionais (FERNANDES; MARZIALE, 2014).

Quando os participantes foram questionados em uma escala de 1 a 5, para avaliar a equipe que realiza a ginástica laboral, responderam em sua grande maioria, com nota máxima para o grupo (5), sendo assim, 39,1\% $(n=45)$. Mostrase desta forma o quanto é importante estimular os participantes a realizarem a ginástica laboral. Usa-se desta forma, a Ginástica Laboral para incentivar a prática da atividade física como forma de promoção da saúde e desempenho profissional, com a associação de ações em conjunto com a empresa também é possível diminuir o absenteísmo e presenteísmo, sedentarismo, o controle do 
estresse e a melhoria da qualidade de vida de uma forma geral, como também melhora a flexibilidade, mobilidade, postura, fadiga e relacionamentos (MOURA, 2015).

Em relação aos fatores que dificultam ou estimulam a sua participação nas atividades de ginástica laboral, os participantes poderiam marcar mais de uma alternativa, quando não houvesse como marcá-la, havia um local onde estes poderiam escrever ou sugerir outros fatores. Nesta questão, diversos foram os motivos relacionados que foram assinalados ou escritos, sendo os mais citados, o horário em que a equipe passa no setor com $33 \%(n=38)$ e a "não tenho dificuldades em participar das atividades de ginástica laboral, conseguindo realizá-las sempre que oferecidas", com 33\% (n=38). Alguns outros fatores também foram citados, como o tamanho da sala $0,9 \%(n=1)$, horário $33 \%(n=38)$ o qual é incompatível com o momento e a não participação devido ao fato de sentir-se exposto durante as atividades $7 \%(n=8)$. Horários de trabalho: a gestão dos tempos e o acompanhamento do trabalhador devem ser especialmente cuidados nos casos cujo contrato de trabalho preveja "períodos de prevenção". Participação/controle: aumentar o nível de controle sobre os tempos de trabalho, férias, pausas, entre outros. Permitir, dentro do possível, que os trabalhadores participem em decisões relacionadas com o posto de trabalho e distribuição do trabalho. Tempo de lazer: maximizar o tempo de lazer para repor o equilíbrio físico e mental de forma adaptativa (FERNANDES; PEREIRA, 2016).

De uma forma geral, para Kretzschmar e colaboradores (2012), um programa de promoção de saúde bem desenhado e adequadamente administrado traduz-se em empregados mais saudáveis. Consequentemente, a quantidade de licenças-saúde será menor e o resultado final será um número maior de horas produtivas.

\section{CONCLUSÃO}

De acordo com os resultados encontrados, é possível concluir que o Projeto de Saúde do Trabalhador conseguiu atingir boa parte dos trabalhadores da Instituição, melhorando a qualidade da saúde, em todos os seus níveis, durante a sua jornada de trabalho.

A idade dos participantes neste estudo indica diferentes públicos que o projeto atinge na Universidade, o que demonstra a importância de refletir sobre as diversas atividades que devem ser realizadas. Também se percebe o reconhecimento do público trabalhador quanto à importância dos programas de incentivo ao movimento corporal, e adaptações ergonômicas do ambiente de trabalho.

Através desse estudo foi possível avaliar as práticas rotineiras de cuidados e prevenção em saúde, atraindo os trabalhadores com atividades e dinâmicas diferenciadas, para que se sintam interessados em participar do 
Projeto de Cuidados em Saúde do Trabalhador. Atualmente é imprescindível a presença do profissional Fisioterapeuta ou de Educação Física em empresas e indústrias. Este pode tornar o ambiente de trabalho mais seguro e ativo, realizando práticas de prevenção e promoção de saúde como a ginástica laboral e análises ergonômicas.

\section{Referências}

ANDRADE, Karine Oliveira; ANDRADE, Priscila Oliveira; LEITE, Lincoln Feitosa; Qualidade de vida dos trabalhadores da área da saúde: Uma revisão de literatura. Revista Científica do ITPAC, Araguaína, v.8, n.1, Pub.1, Janeiro 2015;

BAU, Lucy Mara; KLEIN, Alison Alfred; O reconhecimento da especialidade em fisioterapia do trabalho pelo COFFITO e Ministério do Trabalho/CBO: uma conquista para a fisioterapia e a saúde do trabalhador. Rev. bras. fisioter. 2009, vol.13, n.2, pp.V-VI. ISSN 1413-3555. Disponível em http:/ / dx.doi.org/10.1590/S141335552009000200001;

BRASIL. Ministério da Previdência e Assistência Social. Anuário Estatístico da Previdência Social. Brasília, DF; 2014. Disponível em: http:/ /bit.ly/2eK6o9X;

BRASIL . LEI No 6.367, DE 19 DE OUTUBRO DE 1976. CLT, Disponível em < http:/ / www.planalto.gov.br/ccivil_03/leis/16367.htm > acesso em 18/05/2018;

CARVALHO TN, LESSA MR. Sedentarismo no ambiente de trabalho: os prejuízos da postura sentada por longos períodos. Rev. Elet. Múltiplo Saber. [ISSN 1980-5969] 2014.

FERNANDES, Márcia Astrês; MARZIALE, Maria Helena Palucci; Riscos ocupacionais e adoecimento de trabalhadores em saúde mental. Acta Paulista de Enfermagem, vol. 27, n.6, Pg 539-547; 2014.

FERNANDES, Cláudia; PEREIRA, Anabele; Exposição a fatores de risco psicossocial em contexto de trabalho: revisão sistemática. Rev. Saúde Pública - Pg 50:24; 2016;

GIANDIARDI, Vivian Farehte; Análise do desempenho do membro superior em exercícios de alcance de indivíduos sadios experientes e inexperientes. Anais do Conic-Semesp. Volume 1, Faculdade Anhanguera de Campinas - Unidade 3. ISSN 2357-8904; 2013;

GRANDE, Antônio Jose; SILVA, Valter; Manzatto, Luciane; ROCHA, Túlio Brandão Xavier; MARTINS, Gustavo Celestino; VILELA, Junior; GUANIS, de Barros; Determinantes da qualidade de vida no trabalho: ensaio clínico controlado e randomizado por clusters / Determinants of quality of life at workplace: cluster-randomized controlled trial Rev. bras. cineantropom. desempenho hum. 2013;15(1):27- 37; 
KRETZSCHMAR, Magda A.; BEZERRA, Gabriela das Chagas; BRITO, Larissa Ribeiro; Ginática Laboral, uma opção para o Fisioterapeuta e nova perspectiva para Instituições de Ensino. Revista UNILUS Ensino e Pesquisa v. 9, n. 17, jul./dez. 2012.

MELO, B.F.; SOUZA, A.C.A.G.; FERRITE, S.; BERNARDES, K.O. Atuação do fisioterapeuta nos Centros de Referência em Saúde do Trabalhador: indicadores das notificações dos Dort. Fisioter Pesqui; 24(2):136-142; 2017;

MOURA, Isabel Cristina de; Ginastica Laboral: qualidade de vida para o trabalhador produtividade para empresa; Ariquemes; FAEMA, 2015.

Organização Mundial da Saúde. Disponível em <http:/ / cemi.com.pt/2016/03/04/ conceito-de-saude-segundo-oms-who/ > . Acesso em 31/01/2018;

Organização Mundial da Saúde. Disponível em: Global recommendations on physical activity for health. Geneva: World Health Organization; 2010. Acesso em 29/05/2018;

GALANO, Bruno; TINUCCI, Taís; Sedentarismo, exercício físico e doenças crônicas. Rev. bras. Educ. Fís. Esporte, São Paulo, v.25, p.37-43, dez. 2011.

ROCHA, Saulo Vasconcelos; PLE, Ana Clara Souza; CARDOSO, Jefferson Paixão; AMORIM, Camila Rego; CARNEIRO, Lélia Renata das Virgens; VILELA, Alba Benemérita Alves; Nível de atividade física entre funcionários de uma Instituição de Ensino Superior da Bahia. Ulbra e Movimento (REFUM), Ji-Paraná, v.2 n.1 p.16-29, jan/mar. 2011;

SANTOS, Andréia Fuentes Dos.; ODA, Juliano Yasuo; NUNES, Ana Paula Mori.; GONÇALVES, Luciano.; GARNÉS, Fabrícia Lorca dos Santos; Benefícios da ginástica laboral na prevenção dos distúrbios osteomusculares relacionados ao trabalho. Arq. Ciênc. Saúde Unipa;, Umuarama, v. 11, n. 2, p. 99-113; 2007;

SANTOS, Anselmo Luis dos; GIMENEZ, Denis Maracci; Inserção dos Jovens no Mercado de Trabalho. Estudos Avançados, nº 29, 2015;

SANTOS, Edilâine de Fátima Augusto; Avaliação fisioterapêutica no ambiente de trabalho: Método de prevenção e promoção da qualidade de vida do trabalhador; Faculdade de Pindamonhangaba; Pindamonhangaba SP; 2017;

SANCHES, Elizabeth Navas; CUTOLO, Luiz Roberto Agea; SOARES, Pamela; SILVA, Rosana Marques da; Organização do trabalho, sintomatologia dolorosa e significado de ser portador de LER/DORT. Psicol. Argum; 28(63), 313-324; 2010;

SERRA, Maisa Venturoso Gongora Buckeridge; PIMENTA, Lorrana Campos; QUEMELO, Paulo Roberto Veiga; Ginástica Laboral: Uma revisão da literatura. Revista Pesquisa em Fisioterapia. 197-205; 2014;

VERONESI JÚNIOR, José Ronaldo. Fisioterapia do Trabalho: Cuidando da saúde funcional do trabalhador. Ed Andreoli, 2 ed. São Paulo, 2014; 
VITTA, Alberto de; DE CONTI, Marta Helena Souza; TRIZE, Debora de Melo; QUINTINO, Natasha Mendonça; PALMA, Roger; SIMEÃO, Sandra Fiorelli de Almeida Penteado; Sintomas musculoesqueléticos em motoristas de ônibus: prevalência e fatores associados. Fisioter. Mov vol.26 no.4; 2013. 